\title{
ARTICLE
}

Received 7 Aug 2014 | Accepted 7 Jan 2015 | Published 25 Feb $2015 \quad$ DOl: 10.1038/ncomms7230

\section{Stable silicon-ionic liquid interface for next-generation lithium-ion batteries}

\author{
Daniela Molina Piper ${ }^{1, \star}$, Tyler Evans ${ }^{1, \star}$, Kevin Leung ${ }^{2}$, Tylan Watkins ${ }^{3}$, Jarred Olson ${ }^{4}$, Seul Cham Kim ${ }^{5}$, \\ Sang Sub Han ${ }^{5}$, Vinay Bhat ${ }^{4}$, Kyu Hwan Oh ${ }^{5}$, Daniel A. Buttry ${ }^{3} \&$ Se-Hee Lee ${ }^{1}$
}

We are currently in the midst of a race to discover and develop new battery materials capable of providing high energy-density at low cost. By combining a high-performance Si electrode architecture with a room temperature ionic liquid electrolyte, here we demonstrate a highly energy-dense lithium-ion cell with an impressively long cycling life, maintaining over $75 \%$ capacity after 500 cycles. Such high performance is enabled by a stable half-cell coulombic efficiency of $99.97 \%$, averaged over the first 200 cycles. Equally as significant, our detailed characterization elucidates the previously convoluted mechanisms of the solid-electrolyte interphase on Si electrodes. We provide a theoretical simulation to model the interface and microstructural-compositional analyses that confirm our theoretical predictions and allow us to visualize the precise location and constitution of various interfacial components. This work provides new science related to the interfacial stability of Si-based materials while granting positive exposure to ionic liquid electrochemistry.

\footnotetext{
${ }^{1}$ Department of Mechanical Engineering, University of Colorado at Boulder, Boulder, Colorado 80309, USA. ${ }^{2}$ Sandia National Laboratories, Albuquerque, New Mexico 87185, USA. ${ }^{3}$ Department of Chemistry and Biochemistry, Arizona State University, Tempe, Arizona 85287, USA. ${ }^{4}$ Boulder lonics Corporation, 18300 West Highway 72, Arvada, Colorado 80007, USA. ${ }^{5}$ Department of Material Science and Engineering, Seoul National University, Seoul 151-742, Korea.

* These authors contributed equally to this work. Correspondence and requests for materials should be addressed to S.-H.L. (email: sehee.lee@colorado.edu).
} 
W hile rechargeable lithium-ion batteries (LIBs) have dominated the portable electronics market for nearly a decade, they have failed to gain widespread commercial success in high-power and high-capacity applications. Industry and academia alike have been unable to develop a battery capable of meeting the growing societal and environmental demand for safe, high energy-density, long-lasting energy storage systems ${ }^{1-5}$. Such systems could serve to expedite a smooth transition to an electrified transportation market and enable intermittent renewable energy resources, both of which have been gaining attention in our increasingly carbonconstrained world. The search is on for the next generation of electrode materials that will meet such guidelines in a cost effective and efficient manner ${ }^{6-8}$.

Recently, silicon has been identified as one of the most attractive high-energy anode materials for LIBs. Silicon's low working voltage and high-theoretical specific capacity of $3,579 \mathrm{mAh} \mathrm{g}^{-1}$, nearly ten times higher than that of state-ofthe-art graphite anodes, have encouraged widespread research efforts aimed at developing a viable Si-based electrode ${ }^{9-12}$. The substantial gains in specific and volumetric capacity simply through the implementation of an active material such as Si offer a glimpse into the future of lighter and smaller batteries.

Despite the advantages of the $\mathrm{Si}$ electrode, a number of challenges impede its commercialization. Many of these challenges are associated with the Si material's severe volume expansion during lithiation. While the commercialized graphite electrode expands $\sim 10-13 \%$ during lithium intercalation ${ }^{13,14}$, Si expansion amounts to nearly $300 \%$, generating structural degradation and instability of the all-important solid-electrolyte interphase $(\mathrm{SEI})^{12,15}$. Such instabilities ultimately shorten the battery life to inadequate levels. Degradation of the active material can be mitigated by incorporating materials $<150 \mathrm{~nm}$ (ref. 16); however, research is yet to develop a practical solution to expansion-induced breaking of conduction channels, active material isolation and continuous SEI reformation ${ }^{17,18}$.

Pioneering works have found some success in addressing material instability through the nanostructural design of electrode architectures capable of reducing expansion and its consequences ${ }^{15,19-26}$. The ultimate goal of such research is to incorporate a Si-based negative electrode into a lithium-ion full-cell, requiring the $\mathrm{Si}$ electrode to maintain a half-cell coulombic efficiency (CE) of $>99.994 \%$ for 5,000 cycles ${ }^{15}$. These values, although somewhat unrealistic for current application needs, truly emphasize the importance of half-cell CEs to achieve a long-lasting LIB. Unfortunately, the electrode architectures presented in previous works ${ }^{15,19-26}$, despite providing significant improvements to Si electrode performance, lack the needed CEs largely because the volume change during $\mathrm{Si}$ alloying and de-alloying renders the SEI at the Si-electrolyte interface mechanically unstable.

The SEI layer forms on the anode surface through reductive decomposition of the electrolyte during charging of the battery. $\mathrm{Si}$ anodes suffer extensively from a dynamic SEI that must reform each cycle as expansion during lithiation causes the layer to break ${ }^{9,11}$. Formation of the SEI consumes $\mathrm{Li}^{+}$and depletes electrolyte during every cycle 27 . In contrast to half-cells, which utilize a Li metal counter electrode with an effectively unlimited supply of $\mathrm{Li}^{+}$, full-cells have a limited supply of $\mathrm{Li}^{+}$provided by the cathode. It follows that the continuous breaking and reforming of the SEI layer quickly destroys the cell's cycling performance.

Alternative electrolyte compositions ${ }^{28-31}$ and active material surface treatments ${ }^{32}$ have been studied in the effort to enhance SEI formation on high-capacity anode materials and improve half-cell CEs. In spite of these efforts, the CEs achieved throughout cycling are still insufficient for a long-lasting
Si-based full-cell ${ }^{31,33-35}$ or the methods employed to manufacture the full-cells introduce large excesses of $\mathrm{Li}^{+}$ $(>200 \%)$ into the system that serve to counterbalance the cell efficiency losses over long-term cycling ${ }^{36-38}$. In the effort to design next-generation electrolyte materials, room temperature ionic liquids (RTILs or ILs) are of particular interest due to their low volatilities, negligible vapour pressures, thermal stabilities, high-voltage stability windows and sufficient ionic conductivities $^{39}$. Previous work has reported that RTILs, particularly those consisting of the pyrrolidinium $\left(\mathrm{PYR}_{1 n}^{+}\right)$or 1ethyl-3-methyl-imidazolium $\left(\mathrm{EMIM}^{+}\right)$cation and the bis(trifluoromethanesulfonyl)imide (TFSI $^{-}$) or bis(fluorosulfonyl)imide $\left(\mathrm{FSI}^{-}\right)$anion, are cathodically stable with popular negative electrode materials ${ }^{36,40-42}$ including $\mathrm{Si}$ (refs 29-31). While the compatibility of ILs with such materials has been proven, a clear understanding of their electrochemical properties and interfacial chemistries has not yet been developed. Moreover, relatively little work has been dedicated to the study of the compatibility between RTIL electrolytes and Si-based nanocomposite electrodes, with all published work in this field, to date, investigating Si-RTIL systems in thin film type electrodes ${ }^{29-31}$.

A combinatorial approach, one involving a mechanically resilient electrode architecture merged with an electrolyte capable of forming a favourable SEI, is the most promising option to integrate structural integrity with stable interfacial chemistry in a bulk type Si anode. To this end, we have designed a Si-RTIL system that exhibits a highly stable and resilient SEI, providing a solution to the drawbacks of the Si-anode and enabling the longterm operation of a lithium-ion full-cell with a bulk type Si-based anode. Through a systematic and comprehensive experimental matrix, we have studied the composition and structure of the SEI formed by an $\mathrm{FSI}^{-}$-based IL on our previously reported cyclized-polyacrylonitrile (cPAN)-based Si nanocomposite architecture $(\mathrm{nSi}-\mathrm{cPAN})^{19}$. Using experimental and theoretical data, we propose a mechanism for the formation of the SEI at the Si-RTIL interface and discuss the importance of CE in half-cell configurations. Most notably, this study is highlighted by the groundbreaking demonstration of the highly reversible cycling of a nSi-cPAN/Li $\left(\mathrm{Ni}_{1 / 3} \mathrm{Mn}_{1 / 3} \mathrm{Co}_{1 / 3}\right) \mathrm{O}_{2}$-(L333) full-cell using a $\mathrm{PYR}_{13} \mathrm{FSI}(1.2 \mathrm{M}$ LiFSI) electrolyte.

\section{Results}

Half-cell electrochemical characterization. The simple fabrication, scalability, low volume expansion and structural robustness of our previously reported nSi-cPAN architecture ${ }^{19}$ make it an ideal candidate to merge with a suitable electrolyte system. In pursuit of a stable Si-electrolyte interface, the nSi-cPAN composite was cycled under galvanostatic conditions in RTILs comprising cation-anion combinations known for their cathodic stabilities against various negative electrode materials ${ }^{29-31,36,40-42}$. The cycling performances of the Si-based electrode in RTIL solutions, including PYR $_{13}$ FSI $(1.2 \mathrm{M} \mathrm{LiFSI}), \mathrm{PYR}_{13}$ TFSI $(0.6 \mathrm{M}$ LiTFSI) and EMIMFSI (1.2 M LiFSI), were directly compared with the electrode performance in the commercial EC/DEC ( $1 \mathrm{M}$ $\mathrm{LiPF}_{6}$ ) electrolyte. The results of the preliminary cycling study are presented in Fig. 1, demonstrating the exceptional cycling stability of the nSi-cPAN anodes in $\mathrm{FSI}^{-}$-based ILs and their unprecedented $\mathrm{CE}$ in the $\mathrm{PYR}_{13} \mathrm{FSI}$ system. The high $\mathrm{CE}$ manifested in the PYR $_{13} \mathrm{FSI}$ (1.2 M LiFSI) electrolyte stabilizes after 8 cycles, with an average stable CE of $99.945 \%$ and a charge capacity retention of $76.7 \%$ after 100 cycles (blue profiles, Fig. 1a). While exhibiting stable half-cell cycling, the lower average $\mathrm{CE}$ (98.451\%) observed using an EMIMFSI (1.2 M LiFSI) electrolyte (orange profiles, Fig. 1b) is ascribed to the instability of the 

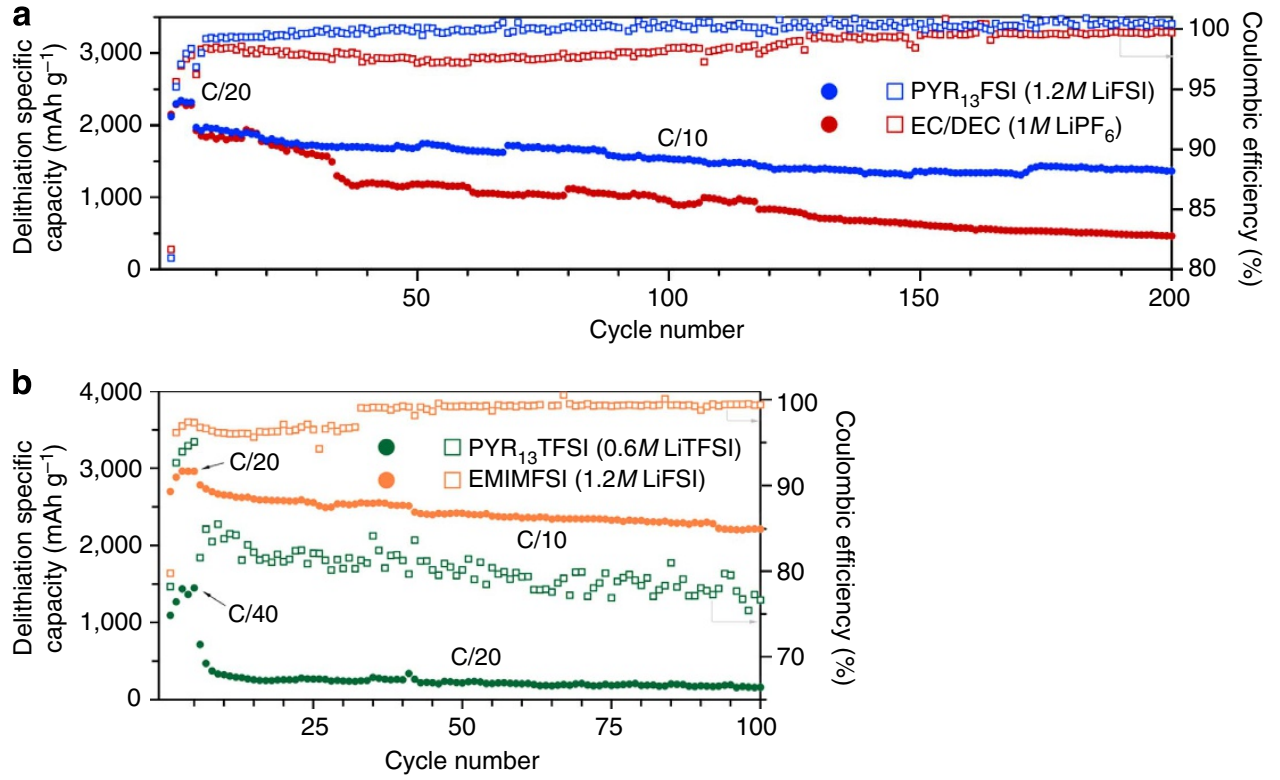

Figure 1 | Galvanostatic performance of various electrolyte systems with nSi-cPAN. (a) Specific capacities and coulombic efficiencies of nSi-cPAN electrode in $\mathrm{PYR}_{13} \mathrm{FSI}(1.2 \mathrm{M} \mathrm{LiFSI})$ and EC/DEC (1 M LiPF $)$. (b) Specific capacities and coulombic efficiencies of $n S i-c P A N$ electrode in PYR 13 TFSI (0.6 M LiTFSI) and EMIMFSI (1.2 M LiFSI) electrolyte systems. Cycling was carried out at room temperature in 2032 coin-type half-cells operated between 0.05 and $1 \mathrm{~V}$ (versus $\mathrm{Li} \mathrm{Li}^{+}$).

$\mathrm{EMIM}^{+}$cation below $1.5 \mathrm{~V}$ (versus $\left.\mathrm{Li} / \mathrm{Li}^{+}\right)^{41}$. Such impressive data contrast that of the cycling behaviour of our nSi-cPAN electrode in a conventional organic electrolyte, which maintains only $45.2 \%$ of its initial charge capacity after 100 cycles with an average stable CE of $97.824 \%$ (red profiles, Fig. 1a), and the rapid capacity fade and low-active material utilization in a TFSI $^{-}$-based IL (green profiles, Fig. 1b). The results obtained with organic electrolyte differ from our previous work ${ }^{19}$ due to the absence of a voltage hold step during cycling, typically required to add stability and increase CE, and a higher-active material mass loading in this study (over double that of our previous work). The chargedischarge profiles generated by cycling the nSi-cPAN in each electrolyte solution are depicted in Supplementary Fig. 1.

The unparalleled CEs of the Si-PYR ${ }_{13}$ FSI system are attributed to the formation of a highly stable SEI. We suggest that the breakdown of the ions present in the electrolyte solutions leads to varying SEI compositions dependent on the ionic make-up of the RTILs. We postulate that the interface formed by the decomposition products of the $\mathrm{FSI}^{-}$-based IL mitigates the continuous SEI formation experienced in organic electrolyte, and this proposal is substantiated by the longer cycling life of the Si-PYR ${ }_{13}$ FSI half-cell (Fig. 1a, blue profile), achieving an average $\mathrm{CE}$ of $99.97 \%$ in 200 cycles. Given the distinct incongruity of the $\mathrm{nSi}$-cPAN electrode with the $\mathrm{TFSI}^{-}$-based electrolyte, the decomposition mechanisms and SEI compositions resulting from ILs comprising TFSI $^{-}$and $\mathrm{FSI}^{-}$were explored using density functional theory (DFT) electronic structure methods.

Theoretical simulation of RTIL reductive decomposition. Mechanisms for the reductive decomposition of the $\mathrm{FSI}^{-}$and TFSI $^{-}$anions on Li metal surfaces and in bulk solution have been examined in the literature $e^{41,43}$. Through parallel modelling treatments in different environments, we are able to compare potential SEI formation pathways in ILs containing both anions. The first type of theoretical study consists of cluster-based, localized basis calculations on isolated $\mathrm{FSI}^{-}$(Fig. 2a) and TFSI $^{-}$(Fig. 2c) anions, and pairs of these ions (Supplementary
Fig. 2), mimicking one-electron reduction pathways in environments that do not react rapidly with the reduced species, including those inside the bulk liquid electrolyte or at cPAN interfaces. The second study consists of periodic boundary condition simulations of $\mathrm{PYR}_{13}^{+} / \mathrm{FSI}^{-}$and $\mathrm{PYR}_{13}^{+} / \mathrm{TFSI}^{-}$ion pairs on either a bare $\mathrm{Li}_{13} \mathrm{Si}_{4}$ slab (010) surface, which mimics RTIL components that may have diffused into the more reactive electrode environments, or the same anions on model cPANcoated $\mathrm{Li}_{13} \mathrm{Si}_{4}$ surfaces. Similar initial bond-breaking pathways are obtained by these modelling treatments; thus, we will focus the following analysis on the study of ion pairs on a lithiated silicon surface. A detailed description of the localized basis calculations (first type of modelling study) is provided in the Supplementary Information and depicted in Supplementary Fig. 2. To model our electrolyte molecules in direct contact with a pristine anode surface ${ }^{4,44}$, we first optimize $\mathrm{PYR}_{13}^{+} / \mathrm{FSI}^{-}$and $\mathrm{PYR}_{13}^{+} / \mathrm{TFSI}^{-}$ion pairs on the $\mathrm{Li}_{13} \mathrm{Si}_{4}$ surface (Fig. 2e,g, respectively). The same model surface was previously studied in the context of fluoroethylene carbonate (FEC) decomposition ${ }^{45}$ and represents a low-potential anode surface with Si directly exposed to the liquid electrolyte, serving as an electron source that can readily reduce electrolyte molecules in its vicinity.

After the geometric optimizations, which do not lead to chemical reaction, $a b$ initio molecular dynamics (AIMD) simulations were initiated at $350 \mathrm{~K}$. The $\mathrm{FSI}^{-}$anion rapidly decomposes within 1.2 ps (Fig. $2 \mathrm{f}$ ). The S-F bond breaks first, releasing $\mathrm{F}^{-}$as shown in Fig. 2b, followed by detachment of the $\mathrm{SO}_{2}$ group, which is expected to undergo further reaction with the anode surface and absorb a second electron. This rapid reaction cascade is reminiscent of the $\mathrm{FSI}^{-}$reactions predicted on Li metal surfaces. ${ }^{43}$

TFSI $^{-}$proves to be much less reactive than $\mathrm{FSI}^{-}$, staying intact on the $\mathrm{Li}_{13} \mathrm{Si}_{4}$ surface for $21 \mathrm{ps}$ at which point it decomposes (Fig. 2d). Neither of the two resulting fragments have a net magnetic moment, indicating that a two-electron reduction has occurred and formed $\mathrm{SO}_{2} \mathrm{CF}_{3}^{-}$and $\mathrm{NSO}_{2} \mathrm{CF}_{3}^{-}$on the electrode surface (Fig. 2h). This prediction correlates with the initial majority product proposed by Markevich et al. ${ }^{41} \mathrm{PYR}_{13}^{+}$ remains inert throughout all of the aforementioned simulations. 
a

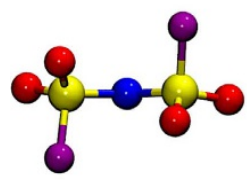

e

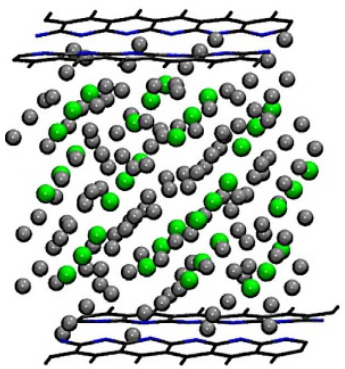

b

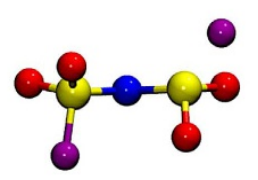

f

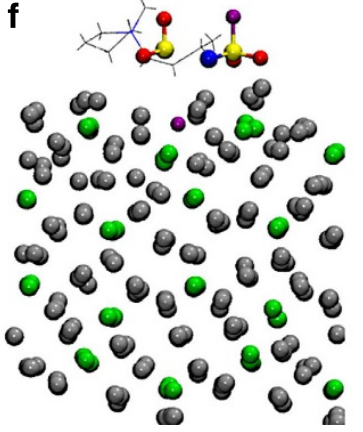

j

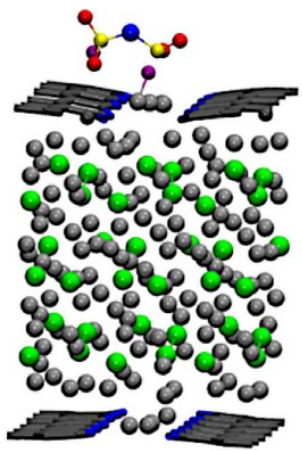

c

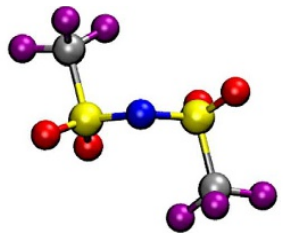

d

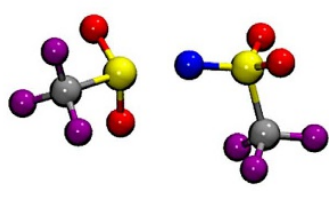

g

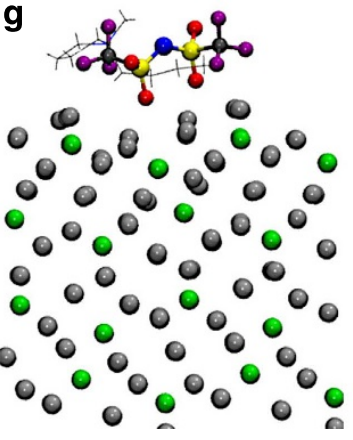

$\mathbf{k}$

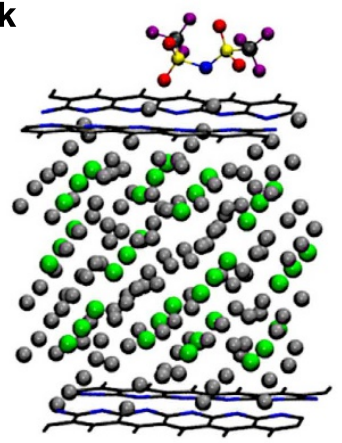

h

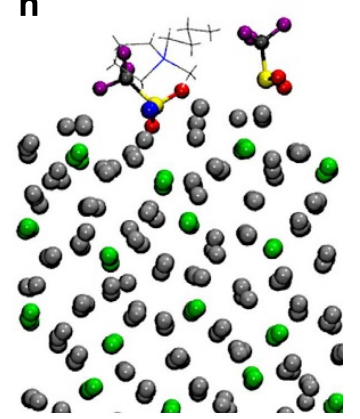

Figure 2 | Decomposition mechanism of $\mathbf{F S I}^{-}$and $\mathbf{T F S I}{ }^{-}$anions on bare and $\mathbf{c P A N}$-coated $\mathbf{L i}_{\mathbf{1 3}} \mathbf{S i}_{\mathbf{4}}$ surface. Ball and stick models of the (a) FSI $^{-}$anion (b) decomposed $\mathrm{FSI}^{2}{ }^{-}$radical di-anion, (c) TFSI ${ }^{-}$anion and (d) decomposed TFSI ${ }^{-}{ }^{-}$di-anion. DFT simulations of the (e) intact PYR $13 / \mathrm{FSI}^{-}$pair on $^{+}$ bare $\mathrm{Li}_{13} \mathrm{Si}_{4}$, (f) decomposed $\mathrm{PYR}_{13}^{+} / \mathrm{FSI}^{-}$pair on bare $\mathrm{Li}_{13} \mathrm{Si}_{4}$, (g) intact $\mathrm{PYR}_{13}^{+} / \mathrm{TFSI}^{-}$pair on bare $\mathrm{Li}_{13} \mathrm{Si}_{4}$ and (h) decomposed PYR $\frac{13}{13} / \mathrm{TFSI}^{-}$pair on bare $\mathrm{Li}_{13} \mathrm{Si}_{4}$. In (e-h) excess electrons on $\mathrm{FSI}^{-}$or TFSI ${ }^{-}$are not added explicitly but come from $\mathrm{Li}_{13} \mathrm{Si}_{4}$. Ball and stick model of the (i) cPAN coating $\mathrm{Li}_{13} \mathrm{Si}_{4}$. DFT simulation of the (j) spontaneous decomposition of $\mathrm{FSI}^{-}$anion on cPAN-coated $\mathrm{Li}_{13} \mathrm{Si}_{4}$, $(\mathbf{k})$ intact TFSI- anion on cPAN-coated $\mathrm{Li}_{13} \mathrm{Si}_{4}$ and (I) decomposed TFSI ${ }^{-}$anion on CPAN-coated $\mathrm{Li}_{13} \mathrm{Si}_{4}$. Li, $\mathrm{Si}, \mathrm{C}, \mathrm{O}, \mathrm{N}, \mathrm{S}$ and $\mathrm{F}$ atoms are depicted as silver, green, grey, red, blue, yellow and purple spheres, respectively. The $\mathrm{PYR}_{13} \frac{1}{3}$ cation is shown as a grey line diagram in the background of (e-h). All panels are optimized geometries except (f,h) which are AIMD snapshots at $T=350 \mathrm{~K}$.

Further confirmation of these anion decomposition mechanisms is provided by also performing calculations on a cPANcoated $\mathrm{Li}_{13} \mathrm{Si}_{4}$ electrode model (Fig. 2i), which more accurately mimics the chemical environment of the experimental electrodes. Owing to the increment of the system size with cPAN coating, the $\mathrm{PYR}_{13}^{+}$counter-ion was omitted in the decomposition simulations. Attempts to optimize $\mathrm{FSI}^{-}$on the surface lead to spontaneous breaking of the same S-F bond (Fig. $2 \mathrm{j}$ ) as observed on the uncoated $\mathrm{Li}_{13} \mathrm{Si}_{4}$ surfaces and in the cluster-based geometry. Figure $2 \mathrm{j}$ has been modified ( $x$-axis CCW rotation of about $90^{\circ}$ ) to display a better perspective of the $\mathrm{FSI}^{-}$anion on the cPAN surface. Supplementary Figure 3 provides the original (non-rotated) perspective of $\mathrm{FSI}^{-}$breakdown on the cPANcoated $\mathrm{Li}_{13} \mathrm{Si}_{4}$ surface.

In contrast, $\mathrm{TFSI}^{-}$is readily optimized on the surface without bond-breaking reactions (Fig. $2 \mathrm{k}$ ). Manually breaking the C-F bond and placement of the resulting $\mathrm{F}^{-}$in the Li-inserted cPAN gap lead to the reconstitution of the C-F bond, showing that the release of $\mathrm{F}^{-}$is not favourable. Instead, breaking S-N bonds leads to energetically favourable configurations (Fig. 2l). This is in accord with our calculations on bare $\mathrm{Li}_{13} \mathrm{Si}_{4}$ surfaces and in the cluster-based geometry.
To summarize our modelling study, we find that $\mathrm{FSI}^{-}$and TFSI $^{-}$undergo quite different decomposition mechanisms on electrochemical reduction. $\mathrm{FSI}^{-}$rapidly releases $\mathrm{F}^{-}$, most likely forming $\mathrm{LiF}$ in the SEI, in combination with the release of $\mathrm{SO}_{2}$, suggesting the formation of an SEI composed of relatively small inorganic compounds. In contrast, TFSI ${ }^{-}$forms different products, including $-\mathrm{SO}_{2} \mathrm{CF}_{3}$ groups, at much slower timescales. While some of the latter reduced fragments may eventually yield $\mathrm{F}^{-}$according to mechanisms proposed by Markevich et al. ${ }^{41}$, slower $\mathrm{F}^{-}$release, similar to the slow $\mathrm{PF}_{6}^{-}$decomposition in organic electrolyte ${ }^{44}$, is expected by TFSI ${ }^{-}$. We speculate that the fast release of $\mathrm{F}^{-}$and $\mathrm{SO}_{2}$ may be correlated to the high cycling performance exhibited by the Si-PYR ${ }_{13} \mathrm{FSI}$ system. This argument dovetails with earlier modelling studies of FEC decomposition, which show that FEC also rapidly releases $\mathrm{F}^{-}$to form $\mathrm{LiF}$, as well as empirical data, showing favourable $\mathrm{Si}$ half-cell cycling behaviour when using FEC as an electrolyte additive in organic carbonate-based electrolyte ${ }^{45}$.

It should be noted that FEC decomposition also releases large organic fragments ${ }^{45}$ not found in the RTIL reduction pathway. Therefore, FEC and $\mathrm{FSI}^{-}$are not expected to yield identical SEI chemical compositions. To fully understand the unique role of the 
$\mathrm{PYR}_{13} \mathrm{FSI}$ as an electrolyte system and SEI former, we have investigated an $\mathrm{EC} / \mathrm{DEC} / \mathrm{FEC}\left(1.5 \mathrm{M} \mathrm{LiPF}_{6}\right)$ electrolyte system with our nSi-cPAN electrode architecture (Supplementary Fig. 4). Despite the significant improvement in half-cell CEs (average stable CE of $99.216 \%$ in the first 100 cycles) compared with the $\mathrm{EC} / \mathrm{DEC}\left(1 \mathrm{M} \mathrm{LiPF}_{6}\right)$ electrolyte, the CEs are still much lower than those exhibited by the $\mathrm{PYR}_{13} \mathrm{FSI}$ electrolyte system. These results illustrate the importance of the fast release of $\mathrm{F}^{-}$for the formation of $\mathrm{LiF}$ in combination with the formation of oxygen and sulfur-based compounds in the proposed SEI. PYR ${ }_{13} \mathrm{FSI}$ (1.2 M LiFSI) becomes, to the best of our knowledge, the first electrolyte system to enable such high half-cell CE values with a high-capacity anode material such as $\mathrm{Si}$.

Interfacial topography and composition. By using electron energy loss spectroscopy (EELS) to study the elemental composition of the surface of $\mathrm{nSi}$-cPAN particles during cycling (16th delithiation), we confirm our DFT predictions and gain insight into the elemental constitution and topography of the proposed SEI. Figure 3 displays high-resolution transmission electron

microscopy (HRTEM) images of the cycled/delithiated nSi-cPAN cross-section (Fig. 3b) with EELS mapping of silicon (Fig. 3a), carbon (Fig. 3c), sulfur (Fig. 3e), fluorine (Fig. 3g), lithium (Fig. 3i) and oxygen (Fig. 3k). The well-defined silhouette of $F$ coating the surface of the Si particles, in combination with the presence of $\mathrm{Li}$, provides further evidence of an SEI composition containing $\mathrm{LiF}$ (refs 35,45), as proposed in literature ${ }^{43,46}$ and found in our DFT simulations. Moreover, the clear mapping of $\mathrm{O}$ over the cPAN surface coating and evidence of $S$ correlates with the proposed reaction of previously determined $\mathrm{FSI}^{-}$-breakdown products, such as $\mathrm{SO}_{2}$ and $\mathrm{LiO}$ (refs 43,46,47). Similar analysis of a conventional Si-based electrode cycled in conventional, organic electrolyte shows no specific adherence of electrolyte decomposition products around the cycled $\mathrm{Si}$ particles (Supplementary Fig. 5).

To elucidate the precise chemical composition of the proposed SEI, X-ray photoelectron spectroscopy (XPS) is utilized to verify the chemical bonding environments of the species observed physically with EELS and simulated through DFT. Alongside our EELS characterization, Fig. 3 displays the deconvolution of the $\mathrm{C}$ 1s (Fig. 3d), S 2p (Fig. 3f), F 1s (Fig. 2h), Li 1s (Fig. 2j) and O 1s

C

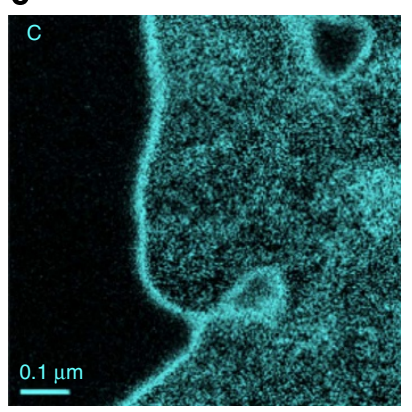

g

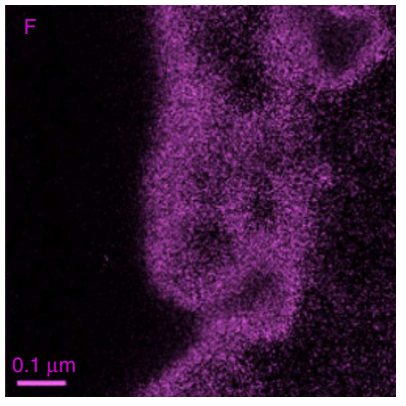

k

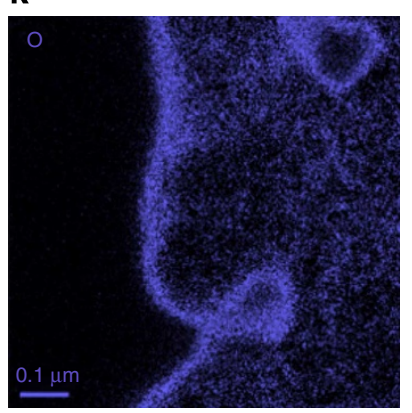

d

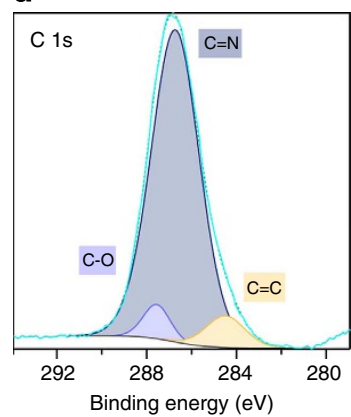

h

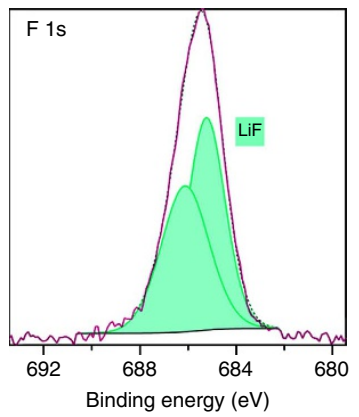

I

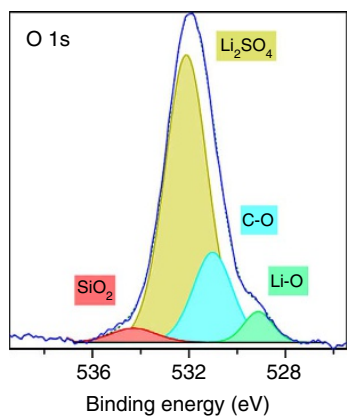

Figure 3 | Solid-electrolyte interphase composition of the Si-PYR $\mathbf{R}_{\mathbf{1 3}} \mathbf{F S I}$ system. (a) EELS elemental mapping of Si from (b) TEM micrograph of cycled nSicPAN electrode at the 16th delithiation along with EELS elemental mapping and XPS analysis of $(\mathbf{c}, \mathbf{d})$ carbon, $(\mathbf{e}, \mathbf{f})$ sulfur, (g,h) fluorine, (i,j) lithium and $(\mathbf{k}, \mathbf{I})$ oxygen, defining the elemental constitution and favored nucleation sites of the SEl formed. 
(Fig. 2l) XPS spectra. Deconvolution of the C 1s spectrum shows a chemical environment consistent with that of the cyclized-PAN coating, dominated by the decomposition of $\mathrm{C} \equiv \mathrm{N}$ and formation of ladder-like structures of thermally stable pyridine rings, $\mathrm{C}-\mathrm{N}=\mathrm{C}$, and conjugation of the backbone, $\mathrm{C}=\mathrm{C}$ (ref. 19). Deconvolution of the $\mathrm{F}$ 1s and $\mathrm{Li}$ 1s spectra provide direct chemical evidence of the formation of an SEI composition containing $\mathrm{LiF}$ and lithium-oxygen containing species (that is, $\mathrm{LiO}, \mathrm{LiOH})$, consistent with previous studies of SEIs formed by (fluorosulfonyl)imide-based RTILs ${ }^{43,46}$.

Moreover, the deconvolution of the $\mathrm{S} 2 \mathrm{p}$ and $\mathrm{O} 1 \mathrm{~s}$ spectra reveals evidence of the detachment and reaction of the $\mathrm{SO}_{2}$ group from $\mathrm{FSI}^{-}$breakdown, confirming our DFT simulation and our EELS elemental mapping, in which the presence of sulfur- and oxygen-containing species was observed. The $\mathrm{S} 2 \mathrm{p}$ spectrum clearly shows the presence of $\mathrm{SO}_{2}$ and its reaction on the surface of the particles to form sulfates, sulfites and sulfides, consistent with other works ${ }^{43,46,47}$. In addition to revealing the formation of sulfates, such as $\mathrm{Li}_{2} \mathrm{SO}_{4}$ (ref. 47), and lithium-oxygen species, the deconvolution of the $\mathrm{O} 1 \mathrm{~s}$ spectra affirms the formation of carbon-oxygen components assigned to the reaction of $\mathrm{O}$ with the cPAN coating, suggesting the interaction of the SEI components with the coated electrode surface.

Examination of the SEI formation mechanism via mass change. To investigate the formation mechanism of the proposed SEI on the nSi-cPAN electrode, we turn to an examination of the mass changes on this interface during the first charge-discharge cycle using in situ electrochemical quartz crystal microbalance (EQCM). By monitoring mass increases and decreases on the electrode in real time during the first cycle, at which time the SEI forms its foundational structure, we gain an appreciation for the fragility of this interface in the conventional, organic electrolytebased system while further proving the mechanical resilience of the Si-RTIL interface.

Figure 4 conveys EQCM massograms for the nSi-cPAN initial formation cycle in both organic electrolyte (Fig. 4a) and $\mathrm{FSI}^{-}$based IL (Fig. 4b). Both systems reveal two very distinct behaviours during lithiation, as alluded to in our modelling study. The gradual rise in mass of about $43 \mu \mathrm{g} \mathrm{cm}^{-2}$ during the initial $20 \%$ of lithiation in both systems corresponds to the uptake of lithium by $\mathrm{cPAN}^{21}$, other non-faradaic processes and initial alloying of $\mathrm{Li}$ with $\mathrm{Si}$.

Subsequently, the electrodes undergo rapid mass changes, attributed mainly to the decomposition of electrolyte and deposition of decomposition products on the electrode-electrolyte interface. The onset of these rapid mass changes are visible in the voltage trace of each system through the 'potential overshoot' phenomenon, a known artefact of electrolyte decomposition in EQCM experiments (further explained in the Supplementary Information $)^{48}$. The onset of this rapid mass change occurs earlier (20.5\% lithiation) and at a significantly higher rate (reaching $73 \mathrm{~g} \mathrm{~mol}^{-1}$ of $e^{-}$at $57.8 \%$ lithiation) in a conventional organic electrolyte. Mass change per mole of electrons (m.p.e., $\mathrm{g} \mathrm{mol}^{-1}$ of $e^{-}$) values were extracted from data in Supplementary Fig. 6 and a more detailed analysis is provided in the Supplementary Information. This is owed to the lower electrochemical stability of the conventional organic electrolyte as compared with the $\mathrm{PYR}_{13} \mathrm{FSI}$ system, which has a voltage stability window of $7.31 \mathrm{~V}$ (ref. 49). The higher average m.p.e. in the conventional electrolyte system, along with the very slow $\mathrm{F}^{-}$release during EC/DEC $\left(1 \mathrm{M} \mathrm{LiPF}_{6}\right)$ decomposition as proposed in literature ${ }^{44}$, suggests the formation of an SEI composed primarily of broken-down organic molecules. Conversely, the controlled mass gains, lower average m.p.e. (reaching $25 \mathrm{~g} \mathrm{~mol}^{-1}$ of $e^{-}$after $56 \%$ lithiation and raising to $33 \mathrm{~g} \mathrm{~mol}^{-1}$ of $e^{-}$towards the end of lithiation) and fast release of $\mathrm{F}^{-}$and $\mathrm{SO}_{2}$, as demonstrated earlier in this work, of the PYR $_{13} \mathrm{FSI} \quad(1.2 \mathrm{M}$ LiFSI) electrolyte throughout lithiation substantiate our prediction of the formation of an SEI comprising relatively small inorganic compounds such as $\mathrm{LiF}$ and other sulfur- and oxygen-containing species.

After reaching a critical mass of $282 \mu \mathrm{g} \mathrm{cm}^{-2}$, the mass of the Si-conventional organic electrolyte system crashes. The crash in mass could be caused by a number of factors, including the severe volume expansion known to occur in this system causing breakage of the electrode matrix, and the build-up and rupturing

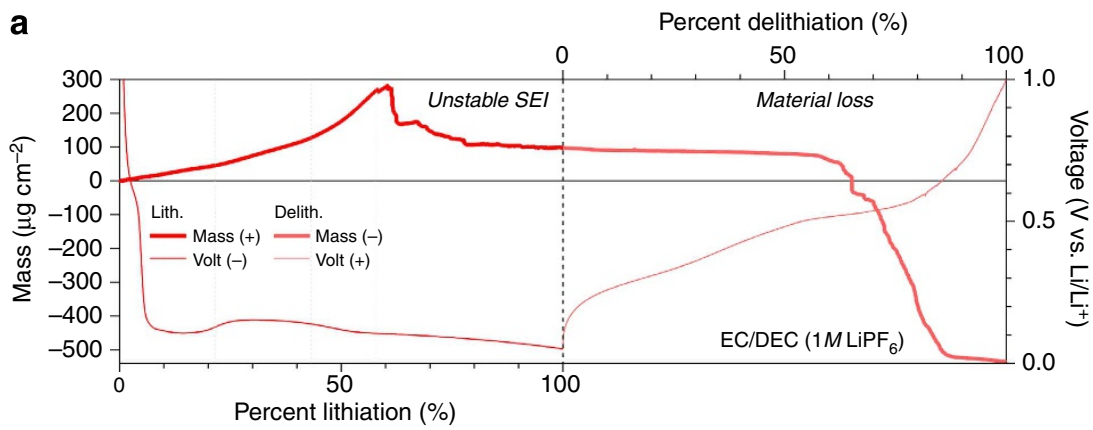

b

Percent delithiation (\%)

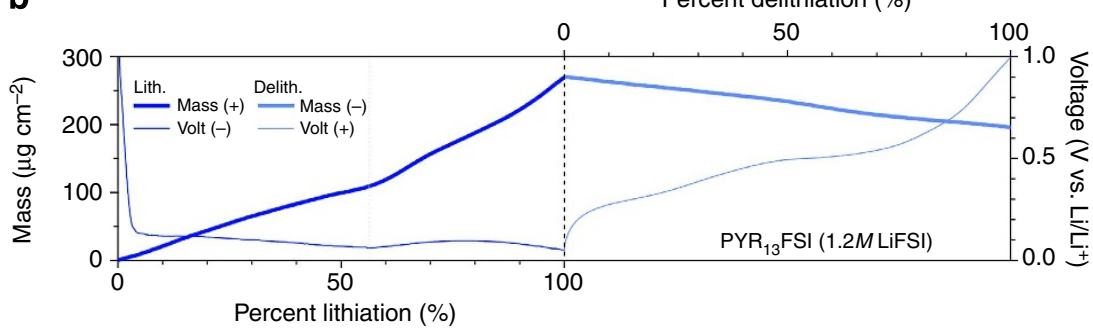

Figure 4 | Mass changes on the nSi-cPAN electrode during the first charge-discharge cycle. EQCM massograms obtained during the initial SEI formation cycle for the nSi-cPAN electrodes cycled in (a) conventional organic electrolyte and (b) PYR ${ }_{13} \mathrm{FSI}(1.2 \mathrm{M}$ LiFSI) electrolyte, along with the voltage traces corresponding to each system. 
of an unstable interfacial layer. During delithiation, contraction of the nSi-cPAN composite leads to further breakage of the electrode matrix and material loss. The inability of this system to exhibit stable mass changes corresponds to the incompatibility of $\mathrm{Si}$ with a conventional electrolyte. In contrast, the Si-RTIL system massogram exhibits more gradual mass growth and loss, with $\sim 73 \%$ of the mass gained during initial lithiation remaining after delithiation. We attribute this behaviour to the irreversible formation of a stable interfacial layer on the $\mathrm{Si}$ electrode, manifesting stable cycling and high CEs throughout an impressive cycling life.

Electrode morphology and volumetric expansion minimization. While the theoretical and experimental data described provide insight into the formation mechanism and composition of the proposed SEI, we turn to a more comprehensive imaging examination to develop a direct understanding of the morphological effects of the PYR ${ }_{13} \mathrm{FSI}$ electrolyte on our Si-based electrode. Consistent with our previous work ${ }^{19}$, EELS and TEM reveal a thin, conformal coating of PAN on the nano-Si particles throughout the uncycled composite (Fig. 5a,b). Our previous work verified the mechanical advantages of the CPAN coating by analysing electrode cross-sections at different stages of cycle life, finding an overall electrode volumetric expansion of only $40 \%$ after full initial lithiation with an EC/DEC (1 M $\left.\mathrm{LiPF}_{6}\right)$ electrolyte ${ }^{19}$. Through the same treatment of electrode crosssection samples taken before (Fig. 5c) and after (Fig. 5d) initial lithiation in a $\mathrm{PYR}_{13} \mathrm{FSI}(1.2 \mathrm{M}$ LiFSI) electrolyte, we find the volumetric expansion of the nSi-cPAN composite to be just $17 \%$. To further investigate this remarkable volume control, TEM micrographs were taken upon initial lithiation (Fig. 5e,f) and after the 16th delithiation (Fig. 5g,h). The TEM images of both the fully lithiated and cycled electrodes show no mechanical deficiencies or morphological changes within the Si particles or
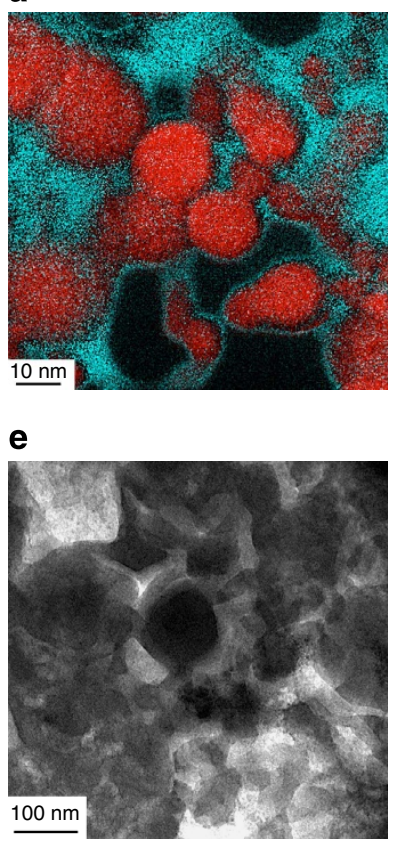

b

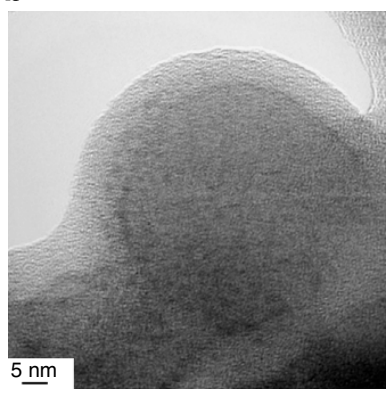

f

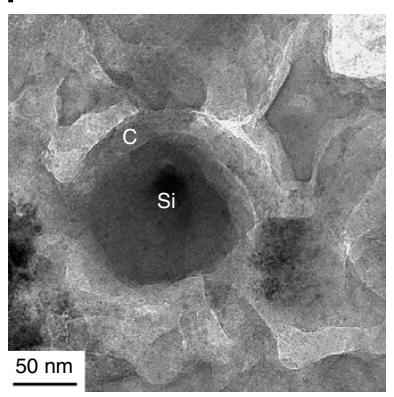

the composite structure. Most notably, after the 16th delithiation the $\mathrm{Si}-\mathrm{PYR}_{13} \mathrm{FSI}$ system exhibits no severance of connection between the $\mathrm{Si}$ particles and cPAN network with striking preservation of the nano-Si spherical shape, contrasting the relatively poor nano-structural preservation of the same electrode in conventional electrolyte. ${ }^{19}$ The impressive structural integrity of the $\mathrm{Si}-\mathrm{PYR}_{13} \mathrm{FSI}$ system is undoubtedly linked to the system's cycling stability, suggesting that the Si-RTIL interface concurrently promotes favourable electrochemistry and structural resilience.

\section{Discussion}

As previously mentioned, the ultimate goal of much electrochemical materials research is to incorporate high-capacity electrodes into a lithium-ion full-cell. Up to this point in our study, we have provided in-depth characterization of the SiPYR $_{13}$ FSI system and proposed a mechanism for the system's stability through a remarkably robust SEI. The most dependable means of substantiating our claim of a stable SEI is to demonstrate the long-term cycling of a full-cell incorporating the Si-PYR ${ }_{13}$ FSI system. Combining this work and our previous study of the compatibility between $\mathrm{PYR}_{13} \mathrm{FSI}$ electrolytes and the L333 cathode chemistry ${ }^{49}$, we have built nSi-cPAN/PYR ${ }_{13}$ FSI (1.2 M LiFSI)/L333 LIBs capable of maintaining high energydensities for an exceptionally long cycling life (see Methods for details on full-cell fabrication).

Figure 6a compares the performance of nSi-cPAN/L333 fullcells assembled with conventional EC/DEC $(1 \mathrm{M} \mathrm{LiPF} 6)$ and PYR $_{13} \mathrm{FSI}$ (1.2 M LiFSI) electrolytes. Both cells presented in Fig. 6 a contain the same electrode mass loading on both cathode and anode (within 10\%) and were operated and controlled under the same parameters for fair comparison. All of the full-cells presented in this work were preconditioned to accurately control the amounts of $\mathrm{Li}$ in the cell and state of charge of the electrodes

c

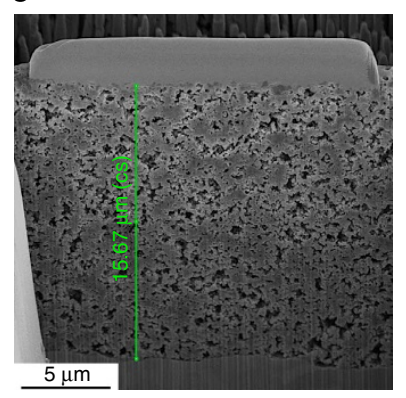

g

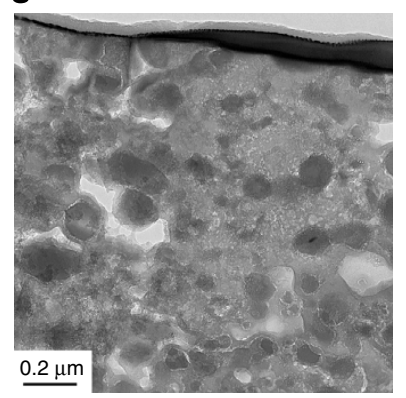

d

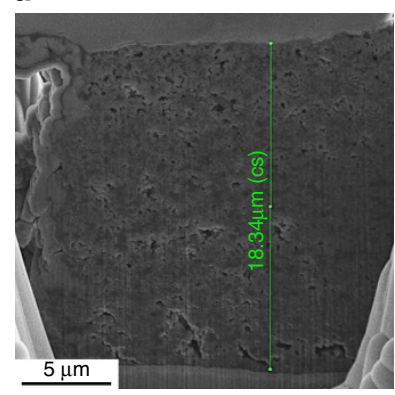

h

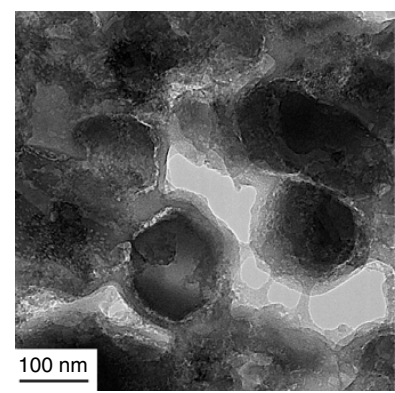

Figure $\mathbf{5}$ | Microstructure of nSi-cPAN and morphological effects of PYR $\mathbf{R}_{\mathbf{1 3}}$ FSI IL on anode. (a) EELS elemental mapping of carbon (cyan) and silicon

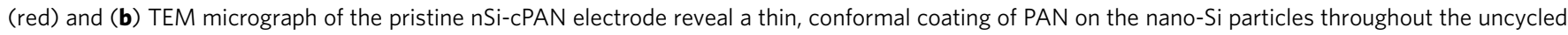
composite. (c,d) FESEM images of electrode cross-sections before (c) and after (d) initial lithiation showing an electrode volume expansion of only $17 \%$. (e-h) TEM micrographs of fully lithiated $(\mathbf{e}, \mathbf{f})$ and 16 th delithiated $(\mathbf{g}, \mathbf{h})$ nSi-cPAN electrodes showing no mechanical deficiencies or significant morphological changes. 

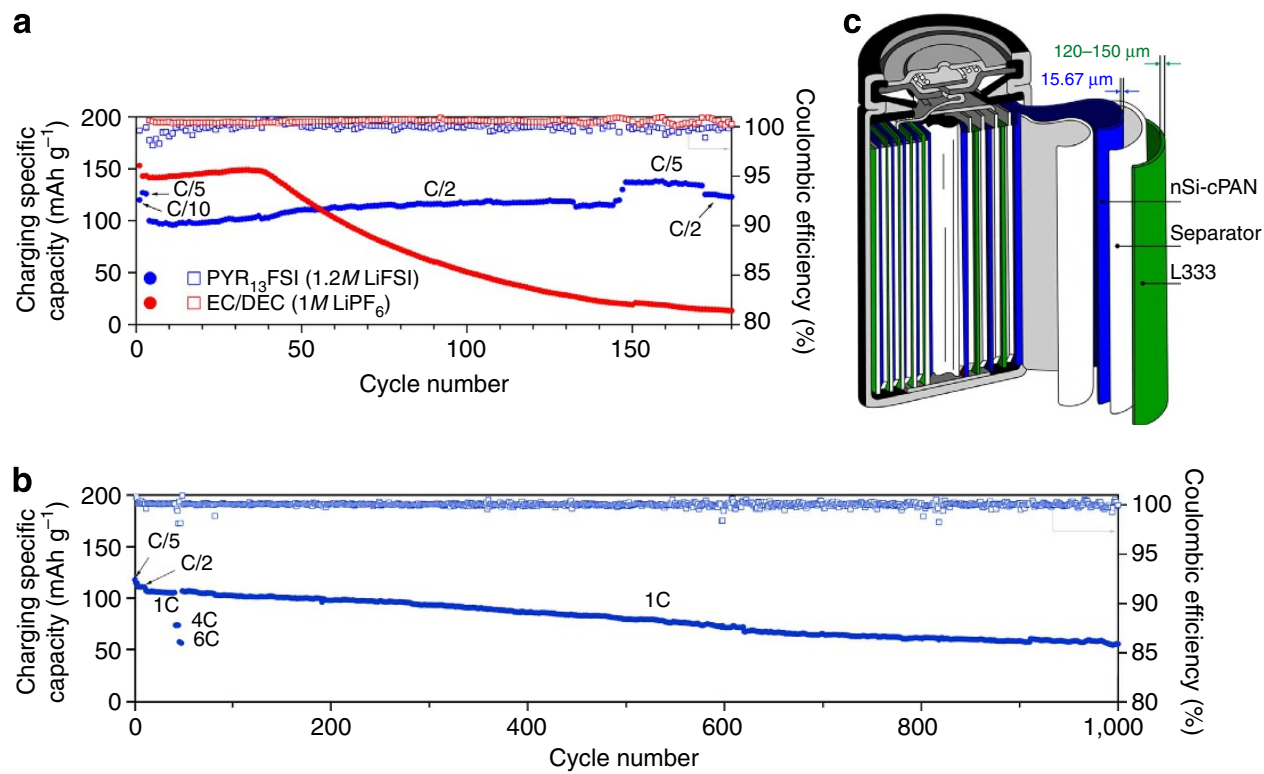

Figure 6 | Full-cell electrochemical performance of $\mathbf{n S i - c P A N / L 3 3 3}$ with PYR $\mathbf{1}_{\mathbf{1 3}} \mathbf{F S I}$ versus EC/DEC electrolyte systems. (a) Specific charge capacities and coulombic efficiencies of $\mathrm{nSi}$-PAN/L333 full-cells assembled with PYR ${ }_{13} \mathrm{FSI}(1.2 \mathrm{M} \mathrm{LiFSI})$ and conventional EC/DEC (1 M LiPF 6 ) electrolytes. (b) nSi-cPAN/PYR ${ }_{13} \mathrm{FSI} / \mathrm{L} 333$ full-cell rate study and long-term cycling. (c) Mock-up of a commercial 18650 cell showing the possibility of incorporating more electroactive material due to the relatively thin nSi-cPAN electrode. Cycling was carried out at room temperature in 2032 coin-type half-cells operated between 2.0 and $4.15 \mathrm{~V}$ (versus $\mathrm{Li} / \mathrm{Li}^{+}$).

(see Methods for details on full-cell fabrication), allowing for accurate comparison between cells. Initial charge capacities of 143.21 and $127.10 \mathrm{mAhg}^{-1}$ (all full-cell specific capacities are normalized with respect to total active material mass) were observed at the $\mathrm{C} / 5$ rate for the $\operatorname{EC} / \mathrm{DEC}(1 \mathrm{M} \mathrm{LiPF} 6)$ and $\mathrm{PYR}_{13} \mathrm{FSI}$ (1.2 M LiFSI) LIBs, respectively. The difference in initial capacity is attributed to the higher resistance of the RTIL electrolyte, though this limitation is countered by unparalleled cycling stability. After 35 cycles, the cell cycled in carbon-based electrolyte degrades rapidly. The degradation, ascribed to low half-cell CEs with an average irreversible charge loss of $2.31 \%$ per cycle (Fig. 1a, red profile), occurs as the system exhausts its supply of Li through continuous SEI breaking and reformation. In contrast, the cell cycled in $\mathrm{PYR}_{13} \mathrm{FSI}(1.2 \mathrm{M} \mathrm{LiFSI})$ electrolyte shows remarkable stability, attributed to the high half-cell CEs, with an average irreversible charge loss of just $0.076 \%$ for the first 100 cycles (Fig. 1a, blue profile) followed by negligible $\mathrm{Li}$ consumption, providing an average full-cell charge capacity of $110.98 \mathrm{mAh} \mathrm{g}^{-1}$ at a rate of $\mathrm{C} / 2$ (Fig. 6a, blue profile). To further investigate the SEI stability of the Si-PYR ${ }_{13}$ FSI system, a full-cell was cycled for longevity with a brief rate study. Figure $6 \mathrm{~b}$ depicts the $\mathrm{nSi}$-cPAN/PYR ${ }_{13}$ FSI $(1.2 \mathrm{M} \mathrm{LiFSI}) / \mathrm{L} 333$ cell run for 1,000 cycles delivering $107.33,74.70$ and $58.26 \mathrm{mAh} \mathrm{g}^{-1}$ at rates of $1 \mathrm{C}$, $4 \mathrm{C}$ and $6 \mathrm{C}$, respectively (1C rate capacity value pertains to the average of the first 40 cycles at this rate).

It is noted that the PYR ${ }_{13}$ FSI RTIL strengthens the performance of a range of previously developed Si-based anode architectures, not just those containing PAN (Supplementary Fig. 7). Moreover, preliminary study of the high-temperature performance of the Si-RTIL system has also yielded promising results (Supplementary Fig. 8), suggesting that the SEI formed by $\mathrm{PYR}_{13} \mathrm{FSI}$ is stable even at elevated temperature. It is understood that the overall energy density of LIBs is limited by the capacity of the positive electrode. While this study demonstrates a significant advancement in the study of LIB anode materials, a high-capacity cathode compatible with the Si-PYR ${ }_{13} \mathrm{FSI}$ pair should be developed to truly realize the benefits of the system. In spite of limitations introduced by the battery cathode capacity, we propose that introducing the $\mathrm{Si}-\mathrm{PYR}_{13} \mathrm{FSI}$ system into a commercial 18650 cell configuration, as shown in Fig. 6c, would allow for incorporation of more electroactive material due to the relatively thin $\mathrm{nSi}-\mathrm{cPAN}$ electrode. On the basis of a commercial battery with a $2 \mathrm{mAh} \mathrm{cm}^{-2}$ areal capacity and nominal voltage of $3.6 \mathrm{~V}$, utilizing the $\mathrm{nSi}-\mathrm{cPAN}$ electrode, which is $<1 / 4$ the thickness of a conventional graphite electrode and needs $<1 / 5$ electroactive material to achieve similar battery capacities, would allow for at least a $35 \%$ increase in overall battery capacity and thus the production of a higher energy-density LIB. Validated by impressive cycling data and a combination of theoretical and experimental results, our approach to developing a stable high energy-density anode-electrolyte system represents important progress towards a safer, higher-performance secondary LIB.

\section{Methods}

Electrode and electrolyte preparation. $\mathrm{nSi}-\mathrm{cPAN}$ and $\mathrm{Li}\left(\mathrm{Ni}_{1 / 3} \mathrm{Mn}_{1 / 3} \mathrm{Co}_{1 / 3}\right) \mathrm{O}_{2}$ electrodes were fabricated according to our procedures described in refs 19 and 49 , respectively. Active material mass loading on both cathode and anode is at least double that of the referenced works. Ionic liquid electrolytes were provided by Boulder Ionics Corporation (USA) and scanned for halide impurities. Impurities $\left(\mathrm{F}^{-}, \mathrm{Cl}^{-}, \mathrm{Br}^{-}, \mathrm{SO}_{4}^{-}\right)$were quantified using a Dionex ICS-1100 chromatograph, calibrated for sensitivities as low as 1 p.p.m. Ion chromatography was performed on all ionic liquids and lithium salts used in this work, and the total impurity content of every solution was calculated based on the mass percentage of electrolyte component in the total mass of electrolyte. The solutions contained $<20$ p.p.m. $(\mathrm{w} / \mathrm{w})$ of moisture and $<10$ p.p.m. (w/w) of halide and metal-ion impurities. One molar $\mathrm{LiPF}_{6}$ in ethylene carbonate:diethyl carbonate (50:50, Soulbrain) was used as a conventional organic electrolyte.

Electrochemical characterization. Electrochemical measurements were carried out using an Arbin BT2000 battery test station. All half-cells were assembled using our prepared nSi-cPAN electrodes as the working electrode and lithium metal foil as the counter electrode. The separator was a glass micro-fibre disc (Whatman GF/F) and the shell was a stainless steel CR2032 coin cell (Pred Materials). The electrolyte systems utilized were EC/DEC ( $\left.1 \mathrm{M} \mathrm{LiPF}_{6}\right), \mathrm{PYR}_{13}$ FSI (1.2 M LiFSI), PYR $_{13}$ TFSI (0.6 M LiTFSI) and EMIMFSI (1.2 M LiFSI). We used a constant current (CC) testing scheme to cycle our half-cells. No voltage holds were utilized during cycling (lithiation or delithiation), preventing the currents applied to relax and supply/remove extra $\mathrm{Li}^{+}$, to highlight the true values of the cells' coulombic efficiencies for each respective current. The half-cells were discharged (lithiated) and charged (delithiated) with various cycling currents (where a $\mathrm{C} / 10$ rate is 
equivalent to $353.6 \mu \mathrm{A} \mathrm{cm}^{-2}$ ) between 0.05 and $1 \mathrm{~V}$ (versus $\mathrm{Li}^{2} \mathrm{Li}^{+}$). Electrochemical measurements of half-cells were all normalized based on the mass of Si-active material in each electrode (typically $1.1-1.3 \mathrm{mg}$ ). We used a constant current constant voltage (CCCV) testing scheme to cycle our full-cells. The fullcells were discharged and charged with various cycling currents (where a $\mathrm{C} / 2$ rate is equivalent to $502.9 \mu \mathrm{A} \mathrm{cm}^{-2}$ for the full-cells in Fig. $6 \mathrm{a}$ and $197.3 \mu \mathrm{A} \mathrm{cm}{ }^{-2}$ for the full-cell in Fig. 6b) between 2 and $4.15 \mathrm{~V}$ (versus $\mathrm{Li} / \mathrm{Li}^{+}$). Electrochemical measurements of full-cells were all normalized with respect to total mass of electroactive material in both cathode and anode electrodes (typically 7-9 mg).

Electronic structure calculations. Two types of calculations were conducted as mentioned in the main text. A detailed description of both the static cluster-based calculation and ab initio molecular dynamics (AIMD) simulations with a bare or cPAN-coated $\mathrm{Li}_{13} \mathrm{~S}_{4}$ slab, and further discussions of the theoretical literature, can be found in the Supplementary Information. cPAN is modelled as graphene strips terminated with $\mathrm{C}-\mathrm{N}=\mathrm{C}$ bonds ${ }^{19}$, with a gap between the terminal $s p^{2}$-hybridized $\mathrm{N}$ atoms to allow for the intercalation of lithium, necessary for the $\mathrm{Li}^{+}$transport (Fig. 2i).

Morphological characterization. FIB (FEI, NOVA200 dual beam system) equipped with a mobile air-lock chamber was used for TEM sample preparation ${ }^{50}$. TEM and EELS analysis were performed with a FEI Tecnai F20 operated at $200 \mathrm{keV}$. A detailed description of our TEM and EELS characterization procedures can be found in ref. 51 .

X-ray photoelectron spectroscopy. XPS spectra were obtained on an AXIS His 165 and ULTRA spectrometer (Kratos) to determine the bonding configurations and chemical state of the elements present on the surface of the cycled nSi-cPAN particles. Argon milling was utilized for depth profiling ( $20 \mathrm{~nm}$ of depth).

Electrochemical quartz crystal microbalance. Similar to the electrode preparation for the coin-cell testing, nSi-cPAN films were coated on 1 inch diameter $\mathrm{Pt}$ $5-\mathrm{MHz}$ resonating quartz crystals (Stanford Research Systems; SRS). The electrochemically active area in the cell was determined to be $1.359 \mathrm{~cm}^{2}$, based on the Pt pattern on the crystal. To mitigate error associated with frequency measurements using thick films on quartz crystals, all nSi-cPAN films were prepared with thicknesses under $10 \mu \mathrm{m}$. The crystals were placed in a SRS QCM200 crystal holder. The holder was modified with PEEK insulation so that a standalone cell, with a volume of $2.5 \mathrm{ml}$, could be enclosed with a lid. The ceiling of the cell was lined with a Li foil counter electrode and connected to a copper wire. All current and potential parameters were consistent with the electrochemical characterizations of the coin-cells.

Full-cell fabrication. Full-cells were fabricated from pre-conditioned electrodes selected based on deliverable capacity. Calculated from the active material mass, nSi-cPAN anodes were fabricated and matched with L333 cathodes such that the total anode capacity was $\sim 160 \%$ of that of the cathode capacity. Both electrodes were then pre-conditioned: the anodes were allowed to run for 10 charge-discharge cycles in a half-cell configuration and were stopped after full lithiation, while the cathodes were allowed to run for 3 charge-discharge cycles in a half-cell configuration and were stopped after full delithiation. The half-cells were then disassembled and the electrodes were used to fabricate 2032 coin-cell (Al-clad cathode cup) type full-cells. This method of pre-conditioning allows for full control of the amount of lithium in the system.

\section{References}

1. Armand, M. \& Tarascon, J. M. Building better batteries. Nature 451, 652-657 (2008)

2. Goodenough, J. B. \& Kim, Y. Challenges for rechargeable Li batteries. Chem Mater. 22, 587-603 (2009).

3. Kang, B. \& Ceder, G. Battery materials for ultrafast charging and discharging. Nature 458, 190-193 (2009)

4. Whittingham, M. S. Lithium batteries and cathode materials. Chem. Rev. 104, 4271-4301 (2004)

5. Tarascon, J. M. \& Armand, M. Issues and challenges facing rechargeable lithium batteries. Nature 414, 359-367 (2001).

6. Tarascon, J.-M. Key challenges in future Li-battery research. Phil. Trans. R Soc. A 368, 3227-3241 (2010)

7. Lee, J.-S. et al. Metal-air batteries with high energy density: Li-air versus $\mathrm{Zn}$-air. Adv. Energy Mater. 1, 34-50 (2011).

8. Song, T. et al. Arrays of sealed silicon nanotubes as anodes for lithium ion batteries. Nano Lett. 10, 1710-1716 (2010).

9. Hatchard, T. D. \& Dahn, J. R. In situ XRD and electrochemical study of the reaction of lithium with amorphous silicon. J. Electrochem. Soc. 151, A838-A842 (2004).
10. Zhang, X. W. et al. Electrochemical performance of lithium ion battery, nano-silicon- based, disordered carbon composite anodes with different microstructures. J. Power Sources 125, 206-213 (2004).

11. Beaulieu, L. Y., Hatchard, T. D., Bonakdarpour, A., Fleischauer, M. D. \& Dahn, J. R. Reaction of Li with alloy thin films studied by in situ AFM. J. Electrochem. Soc. 150, A1457-A1464 (2003).

12. Zhang, W. J. A review of the electrochemical performance of alloy anodes for lithium-ion batteries. J. Power Sources 196, 13-24 (2011).

13. Koyama, Y. et al. Harnessing the actuation potential of solid-state intercalation compounds. Adv. Funct. Mater. 16, 492-498 (2006).

14. Lee, J. H., Lee, H. M. \& Ahn, S. Battery dimensional changes occurring during charge/discharge cycles-thin rectangular lithium-ion and polymer cells. J. Power Sources 113, 833-837 (2003).

15. Wu, H. et al. Stable cycling of double-walled silicon nanotube battery anodes through solid-electrolyte interphase control. Nat. Nanotech. 7, 310-315 (2012)

16. Liu, X. H. et al. Size-dependent fracture of silicon nanoparticles during lithiation. ACS Nano 6, 1522-1531 (2011).

17. Huggins, R. A. Lithium alloy negative electrodes. J. Power Sources 81, 13-19 (1999).

18. Zhang, H. \& Braun, P. V. Three-dimensional metal scaffold supported bicontinuous silicon battery anodes. Nano Lett. 12, 2778-2783 (2012).

19. Molina Piper, D. et al. Conformal coatings of cyclized-PAN for mechanically resilient Si nano-composite anodes. Adv. Energy Mater. 3, 697-702 (2013).

20. Liu, G. et al. Polymers with tailored electronic structure for high capacity lithium battery electrodes. Adv. Mater. 23, 4679-4683 (2011).

21. Molina Piper, D. et al. Hierarchical porous framework of Si-based electrodes for minimal volumetric expansion. Adv. Mater. 26, 3520-3525 (2014).

22. Chan, C. K. et al. High-performance lithium battery anodes using silicon nanowires. Nat. Nanotech. 3, 31-35 (2008).

23. Park, M.-H. et al. Silicon nanotube battery anodes. Nano Lett. 9, 3844-3847 (2009).

24. Molina Piper, D. et al. Reversible high-capacity Si nanocomposite anodes for lithium-ion batteries enabled by molecular layer deposition. Adv. Mater. 26, 1596-1601 (2014).

25. Magasinski, A. et al. High-performance lithium-ion anodes using a hierarchical bottom-up approach. Nat. Mater. 9, 353-358 (2010).

26. Liu, N. et al. A pomegranate-inspired nanoscale design for large-volumechange lithium battery anodes. Nat. Nanotech. 9, 187-192 (2014)

27. Chan, C. K., Ruffo, R., Hong, S. S. \& Cui, Y. Surface chemistry and morphology of the solid electrolyte interphase on silicon nanowire lithium-ion battery anodes. J. Power Sources 189, 1132-1140 (2009).

28. Nie, M., Abraham, D. P., Chen, Y., Bose, A. \& Lucht, B. L. Silicon solid electrolyte interphase (SEI) of lithium ion battery characterized by microscopy and spectroscopy. J. Phys. Chem. C 117, 13403-13412 (2013).

29. Song, J.-W., Nguyen, C. C. \& Song, S.-W. Stabilized cycling performance of silicon oxide anode in ionic liquid electrolyte for rechargeable lithium batteries. RSC Adv. 2, 2003-2009 (2012).

30. Nguyen, C. C. \& Song, S.-W. Characterization of SEI layer formed on high performance $\mathrm{Si}-\mathrm{Cu}$ anode in ionic liquid battery electrolyte. Electrochem. Commun. 12, 1593-1595 (2010).

31. Baranchugov, V., Markevich, E., Pollak, E., Salitra, G. \& Aurbach, D. Amorphous silicon thin films as a high capacity anodes for Li-ion batteries in ionic liquid electrolytes. Electrochem. Commun. 9, 796-800 (2007).

32. Liu, N., Hu, L., McDowell, M. T., Jackson, A. \& Cui, Y. Prelithiated silicon nanowires as an anode for lithium ion batteries. ACS Nano 5, 6487-6493 (2011)

33. Lee, J.-I., Lee, E.-H., Park, J.-H., Park, S. \& Lee, S.-Y. Ultrahigh-energy-density lithium-ion batteries based on a high-capacity anode and a high-voltage cathode with an electroconductive nanoparticles shell. Adv. Energy Mater. 4 in press (2014).

34. Bordes, A., Eom, K. \& Fuller, T. F. The effect of fluoroethylene carbonate additive content on the formation of the solid-electrolyte interphase and capacity fade of Li-ion full-cell employing nano Si-graphene composite anodes. J. Power Sources 257, 163-169 (2014).

35. Ji, L. et al. Graphene/Si multilayer structure anodes for advanced half and full lithium-ion cells. Nano Energy 1, 164-171 (2011).

36. Hassoun, J., Fernicola, A., Navarra, M. A., Panero, S. \& Scrosati, B. An advanced lithium-ion battery based on a nanostructured $\mathrm{Sn}-\mathrm{C}$ anode and an electrochemically stable LiTFSi-Py24TFSI ionic liquid electrolyte. J. Power Sources 195, 574-579 (2010).

37. Hassoun, J., Lee, K.-S., Sun, Y.-K. \& Scrosati, B. An advanced lithium ion battery based on high performance electrode materials. J. Am. Chem. Soc. 133, 3139-3143 (2011).

38. Chae, C., Noh, H.-J., Lee, J. K., Scrosati, B. \& Sun, Y.-K. A high-energy Li-ion battery using a silicon-based anode and a nano-structured layered composite cathode. Adv. Funct. Mater. 24, 3036-3042 (2014).

39. Balducci, A. et al. Development of safe, green and high performance ionic liquids-based batteries. J. Power Sources 196, 9719-9730 (2011). 
40. Fernicola, A., Croce, F., Scrosati, B., Watanabe, T. \& Ohno, H. LiTFSIBEPyTFSI as an improved ionic liquid electrolyte for rechargeable lithium batteries. J.Power Sources 174, 342-348 (2007).

41. Markevich, E. et al. In situ FTIR study of the decomposition of N-butyl$\mathrm{N}$-methylpyrrolidinium bis(trifluoromethanesulfonyl)amide ionic liquid during cathodic polarization of lithium and graphite electrodes. Electrochim. Acta 55, 2687-2696 (2010).

42. Lee, K.-H. \& Song, S.-W. One-step hydrothermal synthesis of mesoporous anatase $\mathrm{TiO} 2$ microsphere and interfacial control for enhanced lithium storage performance. ACS Appl. Mater. Interfaces 3, 3697-3703 (2011).

43. Budi, A. et al. Study of the initial stage of solid electrolyte interphase formation upon chemical reaction of lithium metal and N-Methyl-N-Propyl pyrrolidiniumbis(fluorosulfonyl)imide. J. Phys. Chem. C 116, 19789-19797 (2012).

44. Leung, K. Electronic Structure modeling of electrochemical reactions at electrode/electrolyte interfaces in lithium ion batteries. J. Phys. Chem. C 117, 1539-1547 (2013), and references therein.

45. Leung, K. et al. Modeling Electrochemical decomposition of fluoroethylene carbonate on silicon anode surfaces in lithium ion batteries. J. Electrochem. Soc. 161, A213-A221 (2014), and references therein.

46. Philippe, B. et al. Improved performances of nanosilicon electrodes using the salt LiFSI: a photoelectron spectroscopy study. J. Am. Chem. Soc. 135, 9829-9842 (2013).

47. Xiong, S., Xie, K., Blomberg, E., Jacobsson, P. \& Matic, A. Analysis of the solid electrolyte interphase formed with an ionic liquid electrolyte for lithium-sulfur batteries. J. Power Sources 252, 150-155 (2014).

48. Ryu, Y.-G. et al. Electrochemical behaviors of silicon electrode in lithium salt solution containing alkoxy silane additives. J. Electrochem. Soc. 155, A583-A589 (2008).

49. Evans, T., Olson, J., Bhat, V. \& Lee, S.-H. Effect of organic solvent addition to PYR13FSI + LiFSI electrolytes on aluminum oxidation and rate performance of Li(Ni1/3Mn1/3Co1/3)O2 cathodes. J. Power Sources 265, 132-139 (2014).

50. Son, S.-B. et al. A highly reversible nano-Si anode enabled by mechanical confinement in an electrochemically activated LixTi4Ni4Si7 matrix. Adv. Energy Mater 2, 1226-1231 (2012).

51. Son, S.-B. et al. Microstructure study of electrochemically driven LixSi. Adv. Energy Mater 1, 1199-1204 (2011).

\section{Acknowledgements}

This work is funded by Boulder Ionics Corporation through the Membrane Science, Engineering and Technology (MAST) Center at CU-Boulder, an NSF Industry-
University Cooperative Research Center. This material is based pon work supported by the National Science Foundation under Grant No. IIP-1152040. This work was also supported by the National Science Foundation (NSF, CHE-1231048), by a gran from the Fundamental R\&D Program for Technology of World Premier Materials funded by the Ministry of Knowledge Economy, Republic of Korea (10037919) and by the Research Institute of Advanced Materials (RIAM). Work at ASU was supported by Army Research Office grant number W911NF-11-1-0432. Sandia National Laboratories is a multiprogram laboratory managed and operated by Sandia Corporation, a wholly owned subsidiary of Lockheed Martin Corporation, for the U.S. Department of Energy's National Nuclear Security Administration under contract DE-AC0494AL85000.

\section{Dislaimer}

Any opinions, findings and conclusions or recommendations expressed in this material are those of the author(s) and do not necessarily reflect the views of the National Science Foundation.

\section{Author contributions}

D.M.P. and T.E. contributed equally to this work carrying out experiments, analysing and discussing data, and writing the manuscript; K.L. was supported by Sandia's Laboratory Directed Research and Development program conducting MD simulations, and discussing and writing the MD section of the manuscript; T.W. and J.O. performed QCM, and discussed the QCM section of the manuscript under the guidance and mentoring of D.A.B.; S.C.K. and S.S.H performed FIB, HRTEM and EELS under the guidance and mentoring of K.H.O.; V.B. discussed data and provided technical support; S.-H.L. guided and mentored the whole study and the preparation of the manuscript.

\section{Additional information}

Supplementary Information accompanies this paper at http://www.nature.com/ naturecommunications

Competing financial interests: The authors declare no competing financial interests.

Reprints and permission information is available online at http://npg.nature.com/ reprintsandpermissions/

How to cite this article: Molina Piper, D. et al. Stable silicon-ionic liquid interface for next generation lithium-ion batteries. Nat. Commun. 6:6230 doi: 10.1038/ncomms7230 (2015). 